\title{
Influence of selective comorbidity predictors on functional recovery after hip fracture in an older population
}

\author{
Natasa Radosavljevica, Milica Lazovic ${ }^{\mathrm{a}, \mathrm{b}}$, Dejan Nikolicc, Ivana Petronic ${ }^{c, d}$, Zoran Radosavljevice, Aleksandar Jeremic ${ }^{\mathrm{f}}$
}

\begin{abstract}
Aim. The purpose of the study was to evaluate the influence of four comorbidities from the Cumulative Illness Rating Scale for Geriatrics (CIRS-G) and their severity on functional status outcome after a rehabilitation program measured by the Berg Balance Scale (BBS) in patients with hip fracture.

Methods. The study included 203 patients whose functional status was evaluated by the BBS at admission (Group 1), at discharge (Group 2) and 3 months after discharge (Group 3). Further comorbidity parameters from the CIRS-G were assessed: musculoskeletal impairment, neurological, vascular and cognitive impairment. For the evaluation of CIRS-G severity degree we used the range $0-4$.

Results. At admission there were non-significant differences in mean values of BBS between parameters for the same CIRS-G severity degree. Significant differences between BBS values were noticed in the period after discharge (Group $2_{\text {(musculoskeletal); }} ; P<0.05$, Group $2_{\text {(neurological and cognitive) }} ; P<0.01$ ) and after 3 months of follow-up (Group $3_{\text {(musculoskeletal, neurological and cognitive) }} P<0.01$ ). Higher effects of CIRS-G severity degree on BBS values in Group 2 and Group 3 for neurological impairment $\left(\eta_{\text {Group } 2}^{2}=29.76\right.$ and $\left.\eta_{\text {Group } 3}^{2}=28.35\right)$ and even higher for cognitive impairment $\left(\eta_{\text {Group } 2}^{2}=34.35\right.$ and $\left.\eta_{\text {Group } 3}^{2}=40.63\right)$ were noticed.

Conclusion. Increase in CIRS-G severity degree of cognitive and neurological impairment in patients after hip fracture that were included in the rehabilitation program correlates closely with functional status after discharge and after 3 months of follow-up. Rehabilitation of patients after hip fracture should be mandatory for functional recovery regardless of the comorbidity and functional status.
\end{abstract}

Key words: Berg Balance Scale, CIRS-G, comorbidity, hip fracture, rehabilitation

Received: August 30, 2012; Accepted: November 12, 2012; Available online: November 13, 2012 http://dx.doi.org/10.5507/bp.2012.102

anstitute for Rehabilitation, Belgrade, Serbia

${ }^{b}$ Faculty of Medicine, University of Nis, Nis, Serbia

'Physical Medicine and Rehabilitation, University Childrens Hospital, Belgrade, Serbia

${ }^{d}$ Faculty of Medicine, University of Belgrade, Belgrade, Serbia

eSpecial Hospital for Internal Diseases, Mladenovac, Serbia

fDepartment of Electrical and Computer Engineering, McMaster University, Hamilton, Canada

Corresponding author: Natasa Radosavljevic, e-mail: denikol27@gmail.com

\section{INTRODUCTION}

Elderly patients are at increased risk of falls and hip fractures ${ }^{1}$. It is estimated that between $25-75 \%$ of patients who were independent in everyday physical activities prior to hip fracture are not capable of such functional independence after the fracture ${ }^{2}$. There are several factors that could contribute to the risk of fracture: low bone mineral density, cognitive impairment, modified mobility and oth$\mathrm{ers}^{3}$. Identifying the influences of different comorbidities and their severity in patients after hip fracture on functional recovery could help physicians optimize and effectively introduce the best treatment for the best functional outcome, leading to lower frequency of recurrent falls and thus lowering the mortality.

Assuming that different comorbidities as well as different degrees of disease severity could influence functional recovery and functional outcome, the aim of our study was to evaluate the influence of four comorbidities from the Cumulative Illness Rating Scale for Geriatrics (CIRS-G) and their severity on functional status outcome after the rehabilitation program measured by Berg Balance Scale (BBS) in patients with hip fracture.

\section{MATERIAL AND METHODS}

\section{Study group}

The prospective study encompassed 203 eligible patients that were referred to the specialist rehabilitation facility after hip fracture and included into the rehabilitation program. Before inclusion in the study, eligible participants were informed about the study protocol and rehabilitation program with possible contraindications that might arise over the course of treatment. Informed consent was obtained prior to inclusion. The study was approved by the Institutional Review Board and followed the principles of good clinical practice. Only patients with first hip fracture were included. Therefore, prior to assessing eligibility for study enrollment, participants were examined by a board certified Physician, specialist in Internal Medicine and where appropriate orthopedic 
surgeon and individually planned rehabilitation program was prescribed.

Participant functional status was evaluated by the Berg Balance Scale test on 3 occasions at admission (Group 1 ), at discharge from the rehabilitation center (Group 2) and 3 months after discharge (Group 3).

\section{Functional tests and measures}

The Berg Balance Scale test is used for evaluating 14 tasks where 5 are static and 9 are dynamic, and graded as a 5 points scale from 0 to 4 , where the maximal value for the summarized scores is 56 (ref. $\left.{ }^{4}\right)$. Ability to predict falls in elderly populations suggests the validity of BBS test ${ }^{4}$.

Further comorbidity parameters from the CIRS-G were assessed: musculoskeletal impairment, neurological, vascular and cognitive impairment. For evaluation of severity of these impairments we used the CIRS-G scale for the severity of such impairments, ranging from $0-4$, where 0 is no impairment, 1 mild, 2 moderate, 3 severe and 4 extremely severe impairment. CIRS-G identifies 14 items graded from 0 to 4 , regarding severity, to evaluate comorbidity of participants included in the study ${ }^{5,6}$.

\section{Statistical analysis}

Distribution of participants in different CIRS-G severity degrees regarding evaluated parameters were presented as whole numbers $(\mathrm{N})$. BBS values are presented as means and $\mathrm{SD}(\mathrm{MV} \pm \mathrm{SD})$. One-way ANOVA was done to assess the significance of BBS variability between different parameters (musculoskeletal, neurological, vascular and cognitive) for the same CIRS-G severity degree (0-3). For severity degree 4, a Student's t-test was done. One-way ANOVA was done to assess the significance of the difference in BBS values between different CIRS-G severity degrees within the same parameter (musculoskeletal, neurological, vascular or cognitive). To explain and quantify variability that can be explained between different CIRS-G severity degrees and BBS values in separate CIRS-G parameters (musculoskeletal, neurological, vascular or cognitive) we introduced $\eta^{2}=$ Sum of squares (Between groups) / Sum of squares (Total) x 100, where sum of squares were generated from one-way ANOVA test and results were presented as percentage (\%). Post-hoc Scheffe tests were preformed to test the statistical significance between two different CIRS-G severity degrees within same parameter. For evaluation of functional im- provement between different time of observation within save CIRS-G severity degree of one parameter (musculoskeletal, neurological, vascular or cognitive) we preformed Student's t-test. Statistical significance was set at $P<0.05$.

\section{RESULTS}

The most frequent severity degree of muscle impairment according to CIRS-G in patients that were admitted to the rehabilitation facility after hip fracture was degree 1 with $36.95 \%$, composing almost every third from the evaluated population (Table 1). For neurological impairment it was the population with the degree 0 (72.41\%) and same degree was noticed regarding cognitive impairment $(53.69 \%)$, composing more than two thirds of patients without neurological impairment and more than half without cognitive impairment (Table 1). Regarding the vascular impairment the most frequent were patients with the degree 2 (59.61\%), composing more than half of the evaluated population (Table 1).

When assessing separate parameters from CIRS-G regarding different degrees of severity, we found that at admission there were no significant differences in mean values of BBS between parameters regarding the same degree of severity (Table 2). However it should be noticed that non significantly lowest BBS values for severity degree 1 was for those with neurological impairment $\left(\mathrm{BBS}_{\text {Group } 1}=22.18 \pm 5.28\right)$ as well for those with severity degree $2\left(\mathrm{BBS}_{\text {Group } 1}=22.14 \pm 2.91\right)$ (Table 2$)$. In the group with severity degree 3 , patients with cognitive impairment had non significantly lowest BBS values BBS $_{\text {Group }}$ $=20.56 \pm 4.53$ ) (Table 2). We had no patients with severity degree 4 both for regarding muscular impairment and vascular impairment of observed CIRS-G parameters, but neurologically impaired patients with severity degree 4 had non significantly lowest values of BBS (BBS $=14.88 \pm 4.64)$ than those with cognitive disturbances (Table 2).

In the group after discharge neurologically impaired patients with severity degree 2 had significantly lowest $\mathrm{BBS}$ values $\left(\mathrm{BBS}_{\mathrm{Group} 2}=29.71 \pm 6.92 ; \mathrm{F}\right.$ value $\left.=3.38 ; P<0.05\right)$ and non significantly lowest BBS values in severity degree $1\left(\mathrm{BBS}_{\mathrm{Group} 2}=32.76 \pm 8.23\right)$ when all 4 evaluated comorbidity parameters compared, as well for severity degree $4\left(\mathrm{BBS}_{\mathrm{Group} 2}=17.25 \pm 4.89\right)$ versus group with cognitive

Table 1. Distribution of frequencies in groups of participants at different times of observation regarding CIRS-G severity degree.

\begin{tabular}{cccccc}
\hline \multirow{2}{*}{$\begin{array}{c}\text { BBS } \\
\text { groups }\end{array}$} & $\begin{array}{c}\text { Severity due } \\
\text { to CIRS-G } \\
\text { (degree) }\end{array}$ & $\begin{array}{c}\text { Musculoskeletal } \\
\text { impairment }\end{array}$ & $\begin{array}{c}\text { Neurological } \\
\text { impairment }\end{array}$ & $\begin{array}{c}\text { Vascular } \\
\text { impairment }\end{array}$ & $\begin{array}{c}\text { Fognitive } \\
\text { impairment }\end{array}$ \\
\cline { 3 - 6 } & 0 & 62 & 147 & 19 & 109 \\
Group 1 & 1 & 75 & 17 & 28 & 40 \\
Group 2 & 2 & 37 & 14 & 121 & 26 \\
Group 3 & 3 & 29 & 17 & 35 & 18 \\
& 4 & 0 & 8 & 0 & 10 \\
\hline
\end{tabular}


impairment (Table 2). In the group with severity degree 3, patients with cognitive impairment had non significantly lowest BBS values $\left(\mathrm{BBS}_{\text {Group } 2}=26.22 \pm 7.71\right.$ ) (Table 2).

Tree months after discharge, group with vascular impairment with severity degree 0 had significantly lowest $\mathrm{BBS}$ values $\left(\mathrm{BBS}_{\text {Group } 3}=37.89 \pm 11.58 ; \mathrm{F}\right.$ value $=2.64$; $P<0.05)$ (Table 2). Group with severity degree $2\left(\mathrm{BBS}_{\text {Group }}\right.$ $=32.46 \pm 10.12 ; \mathrm{F}$ value $=3.61 ; P<0.05)$ and severity degree $3\left(\mathrm{BBS}_{\text {Group } 3}=26.89 \pm 9.11 ; \mathrm{F}\right.$ value $\left.=3.03 ; P<0.05\right)$ had significantly lowest BBS values compared to other 3 CIRS-G parameters (Table 2). As for the previous groups regarding the time of evaluation, neurologically impaired patients with severity degree 4 had non significantly lowest values of $\mathrm{BBS}\left(\mathrm{BBS}_{\mathrm{Group} 3}=15.88 \pm 4.79\right)$ than those with cognitive disturbances (Table 2).

For the patients with muscular impairment it is noticed that there is not significant difference between BBS values regarding different degrees of severity graded by CIRS-G at the admission (Group 1), however, significant fluctuations were noticed in the period after discharge (Group 2; $P<0.05$ ) and after 3 months of follow-up (Group 3; $P<0.01$ ) (Table 3). Same applies for the patients with neurological or cognitive impairments, but at discharge (Group 2) there was higher significant variations then in the group with muscular impairment (Group 2; $P<0.01$; and Group 3; $P<0.01$ ). (Table 3 ). We found non significant variations in the BBS values between different degrees of severity for patients with vascular impairment (Table 3). The effects size of the CIRS-G severity degree on BBS values is quite small for all comorbidity parameters in group at admission (Group 1), and in groups at discharge and after 3 months of follow-up for muscle and vascular impairment ( $\eta 2$ values in Table 3 ). There are higher effects of CIRS-G severity degree on BBS values in Group 2 and Group 3 for neurological impairment $\left(\eta_{\text {Group } 2}^{2}=29.76\right.$ and $\left.\eta_{\text {Group3 }}^{2}=28.35\right)$ and even higher for cognitive impairment $\left(\eta_{\text {Group } 2}^{2}=34.35\right.$ and $\left.\eta_{\text {Group } 3}^{2}=40.63\right)$ (Table 3).

Preformed Post-hoc Scheffe test (Table 4) pointed out that significant decline in BBS values for the patients with muscular impairment was noticed in the Group 3 between severity degrees $0 / 1(P<0.05)$ as well between severity degrees $0 / 3(P<0.05)$. Significant decline in BBS values for patients with neurological impairment was noticed in the Group 2 between severity degrees $0 / 2(P<0.05) ; 0 / 3$ $(P<0.05)$ and $0 / 4(P<0.01)$ as well between $1 / 4 ; 2 / 4 ; 3 / 4$ $(P<0.01)$ and in Group 3 between severity degrees $0 / 3$; $0 / 4 ; 1 / 4 ; 2 / 4 ; 3 / 4(P<0.01)$ (Table 4$)$. We found no signifi-

Table 2. BBS mean values in different time of observation for separate CIRS-G parameters regarding severity degree.

\begin{tabular}{llccccc}
\hline BBS & $\begin{array}{l}\text { CIRS-G } \\
\text { groups } \\
\text { degerity }\end{array}$ & $\begin{array}{c}\text { Musculoskeletal } \\
\text { impairment }\end{array}$ & $\begin{array}{c}\text { Neurological } \\
\text { impairment }\end{array}$ & $\begin{array}{c}\text { Vascular } \\
\text { impairment }\end{array}$ & $\begin{array}{c}\text { Cognitive } \\
\text { impairment }\end{array}$ & $\begin{array}{c}\text { Statistical } \\
\text { interpretation }\end{array}$ \\
\hline Group 1 & 0 & $25.10 \pm 4.59$ & $25.99 \pm 17.19$ & $24.68 \pm 6.12$ & $24.24 \pm 3.60$ & $0.47^{\dagger}$ \\
MV \pm SD & 1 & $25.49 \pm 24.04$ & $22.18 \pm 5.28$ & $24.61 \pm 5.06$ & $28.33 \pm 32.48$ & $0.32^{\dagger}$ \\
& 2 & $23.57 \pm 4.25$ & $22.14 \pm 2.91$ & $23.51 \pm 4.36$ & $22.23 \pm 4.97$ & $0.99^{\dagger}$ \\
& 3 & $22.76 \pm 4.54$ & $21.94 \pm 4.38$ & $28.49 \pm 34.79$ & $20.56 \pm 4.53$ & $0.77^{\dagger}$ \\
& 4 & - & $14.88 \pm 4.64$ & - & $16.80 \pm 6.03$ & $0.74^{\dagger \dagger}$ \\
\hline Group 2 & 0 & $36.32 \pm 6.93$ & $36.09 \pm 6.10$ & $33.79 \pm 8.32$ & $37.23 \pm 5.05$ & $1.96^{\dagger}$ \\
MV \pm SD & 1 & $32.85 \pm 7.45$ & $32.76 \pm 8.23$ & $35.61 \pm 7.52$ & $34.45 \pm 6.49$ & $1.21^{\dagger}$ \\
& 2 & $34.92 \pm 7.67$ & $29.71 \pm 6.92$ & $34.58 \pm 7.38$ & $30.88 \pm 8.37$ & $3.38^{\dagger, *}$ \\
& 3 & $31.83 \pm 7.72$ & $30.29 \pm 6.72$ & $31.66 \pm 7.31$ & $26.22 \pm 7.71$ & $2.60^{\dagger}$ \\
& 4 & - & $17.25 \pm 4.89$ & - & $22.00 \pm 6.11$ & $1.79^{\dagger \dagger}$ \\
\hline Group 3 & 0 & $40.98 \pm 9.25$ & $40.48 \pm 8.29$ & $37.89 \pm 11.58$ & $42.72 \pm 6.79$ & $2.64^{\dagger, *}$ \\
MV \pm SD & 1 & $36.00 \pm 10.07$ & $35.47 \pm 10.90$ & $39.50 \pm 9.77$ & $37.45 \pm 8.15$ & $1.06^{\dagger}$ \\
& 2 & $39.24 \pm 10.43$ & $33.57 \pm 10.52$ & $38.49 \pm 9.97$ & $32.46 \pm 10.12$ & $3.61^{\dagger, *}$ \\
& 3 & $34.41 \pm 9.84$ & $31.82 \pm 8.85$ & $34.51 \pm 9.68$ & $26.89 \pm 9.11$ & $3.03^{\dagger, *}$ \\
& 4 & - & $15.88 \pm 4.79$ & - & $20.90 \pm 8.88$ & $1.44^{\dagger \dagger}$ \\
\hline
\end{tabular}

${ }^{\dagger}$ One-way ANOVA (F value); ${ }^{\dagger}$ Student’s t-test (t value); ${ }^{*} P<0.05$

Table 3. Statistical interpretation of BBS values changes in different time of observation for separate CIRS-G parameters regarding severity degree.

\begin{tabular}{|c|c|c|c|c|c|c|c|c|}
\hline \multirow{2}{*}{$\begin{array}{l}\text { BBS } \\
\text { groups }\end{array}$} & \multicolumn{2}{|c|}{$\begin{array}{c}\text { Musculoskeletal } \\
\text { impairment }\end{array}$} & \multicolumn{2}{|c|}{$\begin{array}{c}\text { Neurological } \\
\text { impairment }\end{array}$} & \multicolumn{2}{|c|}{$\begin{array}{c}\text { Vascular } \\
\text { impairment }\end{array}$} & \multicolumn{2}{|c|}{$\begin{array}{c}\text { Cognitive } \\
\text { impairment }\end{array}$} \\
\hline & F value $^{\dagger}$ & $\eta^{2}(\%)$ & F value $^{\dagger}$ & $\eta^{2}(\%)$ & F value $^{\dagger}$ & $\eta^{2}(\%)$ & F value $^{\dagger}$ & $\eta^{2}(\%)$ \\
\hline Group 1 & 0.31 & 0.47 & 1.51 & 2.96 & 0.99 & 1.48 & 1.86 & 3.62 \\
\hline Group 2 & $3.66^{*}$ & 5.23 & $20.97 * *$ & 29.76 & 1.80 & 2.64 & $25.90 * *$ & 34.35 \\
\hline Group 3 & $4.39 * *$ & 6.21 & $19.59 * *$ & 28.35 & 1.70 & 2.50 & $33.87 * *$ & 40.63 \\
\hline
\end{tabular}

${ }^{\dagger}$ Oneway ANOVA; ${ }^{*} P<0.05 ; * * P<0.01$ 
cant variations of BBS values between any two different severity degree groups both at admission, after discharge and 3 month of follow-up (Table 4). For the patients with cognitive impairment significant decline in BBS values persisted among $0 / 2 ; 0 / 3 ; 0 / 4 ; 1 / 3 ; 1 / 4$ and $2 / 4$ severity degree groups $(P<0.01)$ after discharge (Group 2$)$ and after 3 months of follow-up (Group 3 ) between $0 / 1 ; 0 / 2$; $0 / 3 ; 0 / 4 ; 1 / 3 ; 1 / 4$ and $2 / 4$ severity degree groups $(P<0.01)$ (Table 4).

There is significant increase in BBS values for those patients with muscular impairment for severity degrees 0,1 and 2 an all 3 testings, and for severity degree we found statistically significant increase only between Groups 1/2 and Groups 1/3 (Table 5). For patients with neurological impairment those with severity degree 0 showed significant increase of BBS values on all 3 testings, while those with severe degrees (1,2 and 3) gained significant increase only between Groups 1/2 and Groups 1/3 (Table 5). For those with vascular impairment only between Groups 1/2 and Groups 1/3 we found significant BBS increase for severity degrees 0 and 1 , while better performance was noticed for those with severity degree 2 where on all 3 testings we found significant gains in BBS values (Table 5). Patients with most severe degree in our study of vascular complications shown absence of significant BBS values despite physical therapy (Table 5). Participants with severity degree 0 regarding cognitive impairments showed significant increase of BBS values on all 3 testings, while those with severity degrees 2 and 3 gained significant increase only between Groups 1/2 and Groups 1/3 (Table 5). Both patients with most severe degree of impairment from our study referring to neurological or cognitive impairment lacked significant improvement (Table 5).

\section{DISCUSSION}

Patients after hip fracture that were referred to rehabilitation facility with different degrees of muscular impairment significantly increased functional status measured by BBS particularly between admission to rehabilitation center and at discharge as well between admission and 3 months of follow-up. Study participants with lower CIRS-G severity degrees showed significant improvement even after discharge between the period from discharge and 3 months of follow-up (CIRS-G severity degrees 1 and 2), while those with severe degrees (CIRS-G severity degree 3 ) lacked such improvement after discharge. These findings clearly demonstrate how significant impact of rehabilitation program is on functional improvement in the elderly after hip fracture with different degrees of muscular impairment. Previous reports pointed out that neuromuscular stimulation could be of benefit in speeding recovery after hip fracture in the elderly ${ }^{7}$ and thus improving functional status. That corticosteroids in certain populations with CIRS-G severity degrees from 1-3 for musculoskeletal impairment, do not influence functional improvement significantly during rehabilitation can be found in previous reports stating that corticosteroids have no significant influence on functional recovery after hip fracture ${ }^{8}$. Further, it was noticed that muscle mass in women is not associated with functional outcome after hip fracture, contrary to the muscle mass for men that was

Table 4. Multiple correlations of severity degrees in observed parameters in different time of evaluation regarding BBS values.

\begin{tabular}{|c|c|c|c|c|c|c|c|c|}
\hline \multirow[t]{2}{*}{$\begin{array}{l}\text { BBS } \\
\text { groups }\end{array}$} & \multicolumn{2}{|c|}{$\begin{array}{l}\text { Musculoskeletal } \\
\text { impairment }\end{array}$} & \multicolumn{2}{|c|}{$\begin{array}{l}\text { Neurological } \\
\text { impairment }\end{array}$} & \multicolumn{2}{|c|}{$\begin{array}{l}\text { Vascular } \\
\text { impairment }\end{array}$} & \multicolumn{2}{|c|}{$\begin{array}{l}\text { Cognitive } \\
\text { impairment }\end{array}$} \\
\hline & $\begin{array}{l}\text { CIRS-G } \\
\text { severity } \\
\text { degrees }\end{array}$ & $\begin{array}{l}\text { Mean } \\
\text { differ- } \\
\text { ence }^{\dagger}\end{array}$ & $\begin{array}{l}\text { CIRS-G } \\
\text { severity } \\
\text { degrees }\end{array}$ & $\begin{array}{l}\text { Mean } \\
\text { differ- } \\
\text { ence }^{\dagger}\end{array}$ & $\begin{array}{l}\text { CIRS-G } \\
\text { severity } \\
\text { degrees }\end{array}$ & $\begin{array}{l}\text { Mean } \\
\text { differ- } \\
\text { ence }^{\dagger}\end{array}$ & $\begin{array}{l}\text { CIRS-G } \\
\text { severity } \\
\text { degrees }\end{array}$ & $\begin{array}{l}\text { Mean } \\
\text { differ- } \\
\text { ence }^{\dagger}\end{array}$ \\
\hline Group 1 & - & - & - & - & - & - & - & - \\
\hline \multirow[t]{6}{*}{ Group 2} & - & - & $0 / 2$ & $6.37^{*}$ & - & - & $0 / 2$ & $6.35^{* *}$ \\
\hline & & & $0 / 3$ & $5.79^{*}$ & & & $0 / 3$ & $11.01^{* *}$ \\
\hline & & & $0 / 4$ & $18.84^{* * *}$ & & & $0 / 4$ & $15.23^{* *}$ \\
\hline & & & $1 / 4$ & $15.52^{* * *}$ & & & $1 / 3$ & $8.23^{* *}$ \\
\hline & & & $2 / 4$ & $12.46^{* *}$ & & & $1 / 4$ & $12.45^{\text {** }}$ \\
\hline & & & $3 / 4$ & $13.04^{* * *}$ & & & $2 / 4$ & $8.89^{* *}$ \\
\hline \multirow[t]{7}{*}{ Group 3} & $0 / 1$ & $4.98^{*}$ & $0 / 3$ & $8.65^{* *}$ & - & - & $0 / 1$ & $5.27^{* *}$ \\
\hline & $0 / 3$ & $6.57^{*}$ & $0 / 4$ & $24.60^{* *}$ & & & $0 / 2$ & $10.25^{* *}$ \\
\hline & & & $1 / 4$ & $19.60^{* * *}$ & & & $0 / 3$ & $15.83^{* *}$ \\
\hline & & & $2 / 4$ & $17.70^{* * *}$ & & & $0 / 4$ & $21.82^{* *}$ \\
\hline & & & $3 / 4$ & $15.95^{\text {** }}$ & & & $1 / 3$ & $10.56^{* *}$ \\
\hline & & & & & & & $1 / 4$ & $16.55^{\text {** }}$ \\
\hline & & & & & & & $2 / 4$ & $11.56^{* *}$ \\
\hline
\end{tabular}


found to have significant impact on functional outcome indicating that more attention should be paid to the male population after hip fracture particularly in assessing and implementing rehabilitation protocols ${ }^{9,10}$.

Increase in CIRS-G severity degree of neurological impairment in elderly after hip fracture correlates closely with functional status after discharge from rehabilitation facility and after 3 months of follow-up (Table 4). The effects size of CIRS-G severity degrees for neurological impairment on BBS values were among highest particularly in the groups at discharge and at 3 months of follow-up $\left(\eta_{\text {Group } 2}^{2}=29.76 \%\right.$ and $\left.\eta_{\text {Group } 3}^{2}=28.35 \%\right)$.

The results of our study pointed out that for CIRS-G severity degrees there is significant improvement in functional status between admission and discharge period as well as between admission and 3 months post discharge follow-up. However, lack of significant changes in functional improvement is found in these groups between discharge and after 3 months of follow-up. The possible explanation for such result might be found in the fact that patients after moving from rehabilitation facility into home care setting do not follow rehabilitation program advices regularly. As it was expected, in the most severe forms of neurogenic conditions our results pointed out that functional capacity is significantly reduced, influencing non significant improvement in functional recovery even after intensive rehabilitation program and non significant decrease in functional status over the period between discharge and 3 months of follow-up.

Patients with neurological impairment, particularly after stroke, should be individually assessed and included in vigorous rehabilitation programs in order to prevent future falls and consequent new fractures. One factor that increases such risk is residual hemiplegia with muscle weakness and potential loss of balance after the neurological event, while immobilization will result in bone loss and eventual onset of sarcopenia ${ }^{11,12}$. This point of view clearly stresses out how individually planned and implemented rehabilitation program could be of significant benefit in elderly population after hip fracture.

We demonstrated that for patients with severity degrees 1 and 2 of CIRS-G, intrahospital rehabilitation in rehabilitation center has significant influence on recovery, while the post discharge period was followed by significant increase in functional independence only for patients with CIRS-G severity degree 2 . For those with more severe vascular impairment (CIRS-G severity degree 3) we found non significant influence of both intrahospital rehabilitation and rehabilitation after discharge on functional outcome measured by BBS. This observation could be explained by the fact that these patients with severity degree 3 of CIRS-G were not significantly involved into rehabilitation programs due to the vascular problems in order to prevent possible complications.

Increase in CIRS-G severity degree of cognitive impairment in patients after hip fracture that were included in the rehabilitation program correlates closely with functional status after discharge and after 3 months of followup (Table 4). Therefore it can be assumed that cognitive impairment is a negative predictive factor for rehabilitation outcome, as reported ${ }^{13,14}$. Morgen et al..$^{15}$, pointed out that better functional outcome correlates with severity of cognitive impairment shown in our study as well. Beside all evaluated parameters in this study, the effects size of CIRS-G severity degrees for cognitive impairment on BBS values were the highest particularly in the groups at dis-

Table 5. Statistical interpretation of BBS values changes for same severity degree of observed CIRS-G parameters between different times of observation.

\begin{tabular}{|c|c|c|c|c|c|}
\hline \multirow{2}{*}{$\begin{array}{l}\text { CIRS-G } \\
\text { severity } \\
\text { degree }\end{array}$} & \multirow{2}{*}{$\begin{array}{l}\text { Groups due to } \\
\text { the period of } \\
\text { evaluation }\end{array}$} & \multicolumn{4}{|c|}{$\begin{array}{l}\text { Student's t-test } \\
(\mathrm{t} \text { value })\end{array}$} \\
\hline & & $\begin{array}{l}\text { Musculoskeletal } \\
\text { impairment }\end{array}$ & $\begin{array}{l}\text { Neurological } \\
\text { impairment }\end{array}$ & $\begin{array}{c}\text { Vascular } \\
\text { impairment }\end{array}$ & $\begin{array}{c}\text { Cognitive } \\
\text { impairment }\end{array}$ \\
\hline \multirow{3}{*}{0} & Groups 1/2 & $10.63^{* *}$ & $6.71^{* *}$ & $3.84^{* *}$ & $21.87^{* *}$ \\
\hline & Groups 1/3 & $12.11^{* *}$ & $9.21^{* *}$ & $4.40^{* *}$ & $25.10^{* *}$ \\
\hline & Groups 2/3 & $3.17^{* *}$ & $5.17^{* *}$ & 1.25 & $6.77^{* *}$ \\
\hline \multirow{3}{*}{1} & Groups 1/2 & $2.53^{*}$ & $4.46^{* *}$ & $6.42^{* *}$ & 1.17 \\
\hline & Groups 1/3 & $3.49^{* *}$ & $4.53^{* *}$ & $7.16^{* *}$ & 1.72 \\
\hline & Groups 2/3 & $2.18^{*}$ & 0.82 & 1.67 & 1.82 \\
\hline \multirow{3}{*}{2} & Groups $1 / 2$ & $7.87^{* *}$ & $3.77^{* *}$ & $14.21^{* *}$ & $4.53^{* *}$ \\
\hline & Groups 1/3 & $8.46^{* *}$ & $3.92^{* *}$ & $15.14^{* *}$ & $4.63^{* *}$ \\
\hline & Groups 2/3 & $2.03^{*}$ & 1.15 & $3.47^{* *}$ & 0.61 \\
\hline \multirow{3}{*}{3} & Groups $1 / 2$ & $5.45^{* *}$ & $4.29^{* *}$ & 0.53 & $2.69^{*}$ \\
\hline & Groups 1/3 & $5.79^{* *}$ & $4.13^{* *}$ & 0.99 & $2.64^{*}$ \\
\hline & Groups 2/3 & 1.11 & 0.57 & 1.39 & 0.24 \\
\hline \multirow{3}{*}{4} & Groups $1 / 2$ & - & 0.34 & - & 1.92 \\
\hline & Groups $1 / 3$ & - & 0.42 & - & 1.21 \\
\hline & Groups 2/3 & - & 0.57 & - & 0.32 \\
\hline
\end{tabular}


charge and at 3 months of follow-up $\left(\eta^{2}\right.$ Group $2=34.35 \%$ and $\eta_{\text {Group } 3}^{2}=40.63 \%$ ).

Patients without cognitive dysfunctions gained significantly increased BBS values after discharge and after 3 months of follow-up, suggesting that rehabilitation program in this group of participants closely correlates with improvement in functional status. Our study showed that significant increase in functional status was noticed after discharge and after 3 months of follow-up regarding initial values at admission for patients with cognitive impairment with CIRS-G severity degrees 2 and 3. The absence of significant gains on functional status was noticed for those with CIRS-G severity degrees 1 and 4, after discharge, 3 months of follow-up and from the period between discharge and 3 months of follow-up as well. Such significant absence of functional improvement was noticed also for patients with CIRS-G severity degrees 2 and 3, in the period between discharge and 3 months of follow-up. These findings could point out to the possible assumption that CIRS-G severity degree of cognitive impairment correlates with functional improvement, and that rehabilitation program has strong influence on functional recovery particularly in the period between admission and discharge and that achieved functional improvement remains throughout the period of follow-up particularly for those with CIRS-G severity degrees 2 and 3. Previous reports indicated that even though cognitive impairment could not be associated with absolute functional improvement, inclusion into rehabilitation program is justified ${ }^{16}$. Absence of functional improvement in our study for those with CIRS-G severity degree 1 could be explained by the reduced motivation for active involvement into continuous and everyday rehabilitation program. Patients with CIRS-G severity degree 4 could have reduced functional gains probably due to the reduced motivation and/or decreased capacity for functional improvement even after inclusion into rehabilitation program. Previous findings stressed out possible correlation of cognitive impairment at admission and reduced rehabilitation outcome in older patients after hip fracture ${ }^{14,17}$. Taking into consideration these facts, our findings are consistent to the certain degree with previous reports which are pointing out that inpatient rehabilitation program after hip fracture could have benefit on physical function in cognitively impaired patients ${ }^{18}$. These reports clearly indicate the complexisity of the relationship between rehabilitation programs and functional gains in patients with cognitive impairment after hip fracture. Further, it should be stressed out that for optimal functional improvement, continuous and everyday rehabilitation program should be implemented with individual adjustment of therapy intensity and frequency ${ }^{19}$.

Given the facts above, comorbidity predictors as well as their different degree influence the degree of functional recovery after hip fracture pointing out necessity of individual approach in planning the rehabilitation program for these patients. Rehabilitation of patients after hip fracture should be mandatory for functional recovery regardless of comorbidites and functional status as it improves the quality of life.

\section{CONFLICT OF INTEREST STATEMENT}

Author's conflict of interest disclosure: The authors stated that there are no conflicts of interest regarding the publication of this article.

\section{REFERENCES}

1. Trikha V, Rastogi S. Epidemiology and rehabilitation of hip fractures in the geriatric population. IJPMR 2005;16(1):16-9.

2. Magaziner J, Fredman L, Hawkes W, Hebel JR, Zimmerman S, Orwig DL, Wehren L. Changes in functional status attributable to hip fracture: a comparison of hip fracture patients to community-dwelling aged. Am J Epidemiol 2003;157(11):1023-31.

3. Hoang-Kim A, Schemitsch E, Bhandari M, Kulkarni AV, Beaton D. Outcome assessment in hip fracture: evaluation of the practicality of commonly-used outcomes in hip fracture studies. Arch Orthop Trauma Surg 2011;131(12):1687-95.

4. Stevenson TJ, Connelly DM, Murray JM, Huggett D, Overend T. Threshold Berg balance scale scores for gait-aid use in elderly subjects: a secondary analysis. Physiother Can 2010;62(2):133-40.

5. Zekry D, Valle BH, Michel JP, Esposito F, Gold G, Krause KH, Herrmann FR. Prospective comparison of six co-morbidity indices as predictors of 5 years post hospital discharge survival in the elderly. Rejuvenation Res 2010;13(6):675-82.

6. Martocchia A, Indiano I, Tafaro L, Frugoni P, Amici A, Cacciafesta M, Marigliano V, Falaschi P. The evaluation of the presence of comorbidity by the Marigliano-Cacciafesta polypathology scale (MCPS) and the cumulative illness rating scale (CIRS) in elderly subjects with disability. Arch Gerontol Geriatr 2009;49(1):150-2.

7. Lamb SE, Oldham JA, Morse RE, Evans JG. Neuromuscular stimulation of the quadriceps muscle after hip fracture: a randomized controlled trial. Arch Phys Med Rehabil 2002;83(8):1087-92.

8. Di Monaco M, Vallero F, Di Monaco R, Mautino F, Cavanna A. Functional recovery and length of stay after hip fracture in patients taking corticosteroids. Am J Phys Med Rehabil 2004;83(8):633-9.

9. Di Monaco M, Vallero F, Di Monaco R, Tappero R, Cavanna A. Muscle mass and functional recovery in women with hip fracture. Am J Phys Med Rehabil 2006;85(3):209-15.

10. Di Monaco M, Vallero F, Di Monaco R, Tappero R, Cavanna A. Muscle mass and functional recovery in men with hip fracture. Am J Phys Med Rehabil 2007;86(10):818-25.

11. Kanis J, Oden A, Johnell O. Acute and long-term increase in fracture risk after hospitalization for stroke. Stroke 2001;32(3):702-6.

12. Myint PK, Poole KE, Warburton EA. Hip fractures after stroke and their prevention. QJM 2007;100(9):539-45.

13. Lenze EJ, Munin MC, Dew MA, Rogers JC, Seligman K, Mulsant BH, Raynolds DF $3^{\text {rd }}$. Adverse effects of depression and cognitive impairment on rehabilitation participation and recovery from hip fracture. Int J Geriatr Psychiatry 2004;19(5):472-8.

14. Feng L, Scherer SC, Tan BY, Chan G, Fong NP, Ng TP. Comorbid cognitive impairment and depression is a significant predictor of poor outcomes in hip fracture rehabilitation. Int Psychogeriatr 2010;22(2):246-53.

15. Morghen S, Gentile S, Ricci E, Guerini F, Bellelli G, Trabucchi M. Rehabilitation of older adults with hip fracture: cognitive function and walking abilities. J Am Geriatr Soc 2011;59(8):1497-502.

16. Rolland Y, Pillard F, Lauwers-Cances V, Busquère $F$, Vellas $B$, Lafont C. Rehabilitation outcome of elderly patients with hip fracture and cognitive impairment. Disabil Rehabil 2004;26(7):425-31.

17. Heruti RJ, Lusky A, Barell V, Ohry A, Adunsky A. Cognitive status at admission: does it affect the rehabilitation outcome of elderly patients with hip fracture? Arch Phys Med Rehabil 1999;80(4):432-6.

18. Muir SW, Yohannes AM. The impact of cognitive impairment on rehabilitation outcomes in elderly patients admitted with a femoral neck fracture: a systematic review. J Geriatr Phys Ther 2009;32(1):24-32.

19. Radosavljevic N, Nikolic D, Lazovic M, Petronic I, Milicevic V, Radosavljevic Z, Potic J, Ilic-Stojanovic O, Jeremic A. Estimation of functional recovery in patients after hip fracture by Berg Balance Scale regarding the sex, age and comorbidity of participants. Geriatr Gerontol Int. 2012 Jul 5. doi: 10.1111/j.1447-0594.2012.00908.x. 